\title{
COVID-19: Psychosocial Impact on Medical Students. Comparison of Summer-Winter Results
}

\author{
Patricio García-Espinosa ${ }^{1 *}$, Xóchitl Ortiz-Jiménez ${ }^{2}$, Edgar \\ Botello-Hernández ${ }^{1}$, Rebeca Aguayo-Samaniego ${ }^{1}$, Jorge Leíja \\ -Herrera ${ }^{1}$, GECEN Investigators ${ }^{1}$ and Fernando Góngora-Rivera ${ }^{3}$ \\ ${ }^{1}$ Facultad de Medicina, Universidad Autónoma de Nuevo León, Monterrey, México \\ ${ }^{2}$ Facultad de Psicología, Universidad Autónoma de Nuevo León, Monterrey, México \\ ${ }^{3}$ Servicio de Neurología, Hospital Universidario "Dr. José Eleuterio González" \\ Universidad Autónoma de Nuevo León, Monterrey, México \\ *Corresponding Author: Patricio García-Espinosa, Facultad de Medicina, \\ Universidad Autónoma de Nuevo León, Monterrey, México.
}

Received: April 20, 2021

Published: May 25, 2021

C) All rights are reserved by Patricio

García-Espinosa., et al.

\begin{abstract}
Objective: The current SARS-CoV-2 pandemic has caused feelings of anxiety, confusion, and panic among the world's population. Because of these psychological changes resulting from the stress caused by the disease, we sought to investigate the psychological impact of the pandemic on the university student community.

Material and Methods: We surveyed a group of medical students in two different periods of time to compare the psychological and social impact that the pandemic has had on these students, we found a high prevalence of depression and anxiety symptoms in the two stages, being higher prevalence in the winter season. A score of 10 or more was considered as a cut-off point in the GAD-7 and PHQ-9 scales to determine anxiety and depression, respectively. In addition, the Coronavirus Fear Scale and the Positive Experiences of Adversity Scale were used to determine their attitudes towards COVID-19 in winter.

Results: An increase in the number of percentage of students with scores greater than or equal to 10 on both GAD-7 PHQ-9 scales was observed; it was noted that in general students with high scores on these scales had fewer positive experiences and greater number of fears.

Conclusions: It can be observed that the university medical community is a population at risk for mental illnesses; the creation of effective strategies for the detection and control of mental health should be sought; the need for better mental health programs in universities and validation of virtual instruments is evident.
\end{abstract}

Keywords: Anxiety; Depression; College Students; COVID-19; SARS-CoV-2

\section{Abbreviations}

EMC: Coronavirus Fear Scale; EEPA: Positive Experiences on Adversity Scale; GAD-7: General Anxiety Disorder 7; PHQ-9: Patient Health Questionnaire-9

\section{Introduction}

Today, medical students have gone through three semesters with completely virtual classes in a fact considered unprecedented. This represented a pause in practical activities, applicable to the Hospital-School model that prevails in the authors' university, in

Citation: Patricio García-Espinosa., et al. "COVID-19: Psychosocial Impact on Medical Students. Comparison of Summer-Winter Results". Acta Scientific Neurology 4.6 (2021): 102-115. 
which students of clinical courses or also called "Undergraduate Medical Interns" have not had the opportunity to return to their clinical practices except for those who are completing their last year of clinical practice. They have not had the opportunity to return to their clinical practice except for those completing their last year of clinical rotations. In addition to the existence of a high risk of contagion and the indication to stay at home if possible in large cities [1]. It has been described by Cao., et al. [2] Li., et al. [3] in the case of China, Meo., et al. [4] in Pakistan, Ferrell and Ryan [5] in the United Arab Emirates; Alsoufi, A., et al. [6] in Japan, Ngo, H. [7] in the United States of America, the impact that the COVID-19 pandemic has had on medical students in general, proposing that the lack of professional practices, a feeling of lack of preparation to face a pandemic, factors such as the fear of infecting their family, the stress of losing knowledge in face-to-face classes or congresses as factors that are capable of triggering a worsening of mental health. In Latin America and the Caribbean, few authors have addressed the problem in this population (Pérez, A., et al. [8] and Pizan-Campos, E., et al. [9]). On behalf of the authors, a survey was conducted in May 2020 to identify the impact of the pandemic on them. The study found that a high percentage of students felt that the pandemic and the efforts made had produced a decline in mood, loss of social activities, and symptoms of anxiety [10]. High percentages were found in anxiety and depression compared to pre-pandemic times [10]. Among the factors found to be important were having people close to them with COVID-19, having a previously diagnosed psychiatric disorder, using drugs to cope with the quarantine, and an increase in domestic violence. Most of their concerns were due to their family's health and finances [10].

It was considered important to follow up with the students who responded to the initial survey, in addition to using standardized tools for concerns and fears in this follow-up survey, rather than focusing on COVID-19 self-awareness. It is therefore expected to find an increased prevalence of anxiety and depressive symptoms compared to baseline levels, although due to the time that has passed since the onset of the pandemic, and that those who may have been experiencing an adaptive syndrome may have already adapted to the situation, it is expected to find a lower prevalence in the winter compared to the summer.

\section{Materials and Methods}

A cross-sectional follow-up study was conducted, corresponding to a longitudinal study. The population studied comprised stu- dents from the medical school of the authors' center, approaching 7,429 students in twelve semesters. The bulk of the population belongs to students in the first six semesters compared to the clinical semesters or internship semesters $\left(7^{\text {th }}-12^{\text {th }}\right.$ semester $)$. The followup survey was applied to the 384 students taken as the population to be studied above.

A questionnaire with 70 questions was elaborated, the questions were divided into four main variables: 1 ) Social determinants 2) Coronavirus Fear Scale (EMC) 3) Positive Experiences on Adversity Scale (EEPA) 4) Emotional state.

The EMC responses were adapted as Likert-type responses corresponding to no days, some days, more than half of the days, almost every day during the last 2 weeks. While the EEPA responses were made dichotomous for "applicable or not applicable (Sandin, B., et al. [11]).

Generalized Anxiety Disorder-7 (GAD-7; Löwe., et al. [12]). It includes 7 questions that are based on the presence of symptomatology. Responses are Likert-type "no days, some days, more than half the days, almost every day" with a score of $0,1,2,3$ per question. The cut-off point is equal to or higher than 10 points to be considered as anxiety and to initiate treatment. The scale has a sensitivity and specificity of 89\%, respectively; an internal consistency (Cronbach's $\alpha=.92$ ) and Test-Retest reliability (Interclass Correlation = 0.83 ) (Spitzer., et al. [13]).

Patient Health Questionnaire-9 (PHQ-9; Spitzer., et al. [14]). It has 9 questions that are based on the presence of symptoms; responses are Likert-type "no days, some days, more than half the days, almost every day" with a $0,1,2,3$ respectively. A score of 10 is used to initiate treatment assessment for depression. It has a sensitivity and specificity of $88 \%$ respectively, internal consistency (Cronbach's $\alpha=.86-89$ ) and Test-Retest reliability (Interclass Correlation $=.84)$ (Kroenke., et al. [15]).

A literature search was conducted on expected sociopsychological changes during a pandemic, and permission was sought from the appropriate university academic authorities and the university's Ethics and Research Committee. The number P120-0335 was designated for the original article and for the follow-up article. Since no follow-up articles were found in the literature reviewed, it was decided to perform a follow-up on the previously studied 
sample. The EMC instrument was chosen to include the fears previously asked in an unorganized manner and to question positive experiences obtained with the EEPA. Finally, the students previously surveyed were contacted via e-mail, the survey was administered and their informed consent and permission for data dissemination was obtained.

For the analysis, the studied sample was divided into 2 groups to address anxiety staging (with and without) and 2 groups for depression (with and without). Continuous variables were represented by mean $( \pm)$, standard deviation or median and interquartile index, and categorical variables as percentages. To identify the type of distribution of the variables, they were analyzed using the Kolmogorov-Smirnov test. Differences between nonparametric quantitative variables were evaluated using the Mann-Whitney U test and qualitative variables were evaluated using the X2-squared test or Fisher's exact test. Spearman's correlation was used to assess the correlation between variables and having or not having depression and/or anxiety. Binary logistic regression was performed to identify the association between the variables and depression and/ or anxiety staging using the variables that previously had a correlation with a $\mathrm{p}$ value of less than .01. An Excel database was used with ordinal responses that were transcribed into numerical variables and analyzed with Software IBM SPSS version 26.0 [16].

\section{Results and Discussion}

The total number of questionnaires answered for follow-up was 331 students ( $86.2 \%$ of the sample of 384 students). The average age remained at 21 years and the majority were women (68.6\%), which means that fewer men decided to continue with the followup survey, only 9 women did not respond. The percentage of students belonging to the basic semesters of the career remained practically the same. $23.4 \%$ of the sample of the first survey corresponded to students residing outside the metropolitan area of the state; on this occasion, they represented $17.2 \%$ of the sample.

\section{Social determinants}

The percentage of students who would consider using unapproved COVID-19 medications if they became ill increased from $11.7 \%$ to $15.7 \%$, the number of students following the national daily reports decreased to $80.4 \%$, although the percentage of those who believed what was said increased to the same $80.4 \%$. The number of students who reported knowing someone close to them who had experienced COVID-19 increased from $38.5 \%$ to $77.6 \%$, more than doubling in six months, as did those following the confinement measures from $70.6 \%$ to $80.4 \%$, their families from $49.7 \%$ to $55.6 \%$. The percentage of those currently living with their parents was lower (90.6\%), and those who considered their families to have an adequate economic income also decreased to $68 \%$. The number of students who had used illegal drugs to cope with quarantine increased to $13.3 \%$. The most commonly used drug was marijuana (48.9\%) and $92.7 \%$ reported an increased need for support from authorities for the moderate to exaggerated psychological support item. A moderate to exaggerated increase in anxiety prior to the onset of the pandemic was reported by $79.5 \%$. Of the $28.4 \%$ who reported a diagnosis of previous mental disorder $68.4 \%$ reported a moderate to exaggerated subjective worsening of their previous symptoms. 81 students (24.5\%) reported having suicidal thoughts at least once a week (same number, higher percentage than before) (Table 1).

\section{Depression}

$60.4 \%$ of the sample reported a score greater than or equal to 10 , placing them in the group with depression; compared to the previous $43 \%$.

\section{Anxiety}

It was found to be $42.3 \%$ compared to the previous $24.7 \%$. It was found that knowing health personnel who had suffered discrimination was no longer a risk factor for being classified within the group with anxiety (Table 2).

\section{Coronavirus fear scale (EMC)}

The approach was divided for those students who presented a PHQ-9 or GAD-7 greater than or equal to 10 to find out whether they had more fears in general or more conflicts in their social circle (Table 3).

In the group with PHQ-9 equal to or greater than 10, it was observed that fear of the death of a family member was present almost every day in $29 \%$, compared to $13 \%$ who did not present this fear on any day. In those with PHQ-9 less than 10, we found that the relationship is reversed, and they do not fear this any day $30.5 \%$ of the 131 respondents within this group, and 9.2\% fear it every day. Respondents with GAD-7 equal to or greater than 10 have this fear every day $32.1 \%$ and $12 \%$ do not have it any day; in those with 


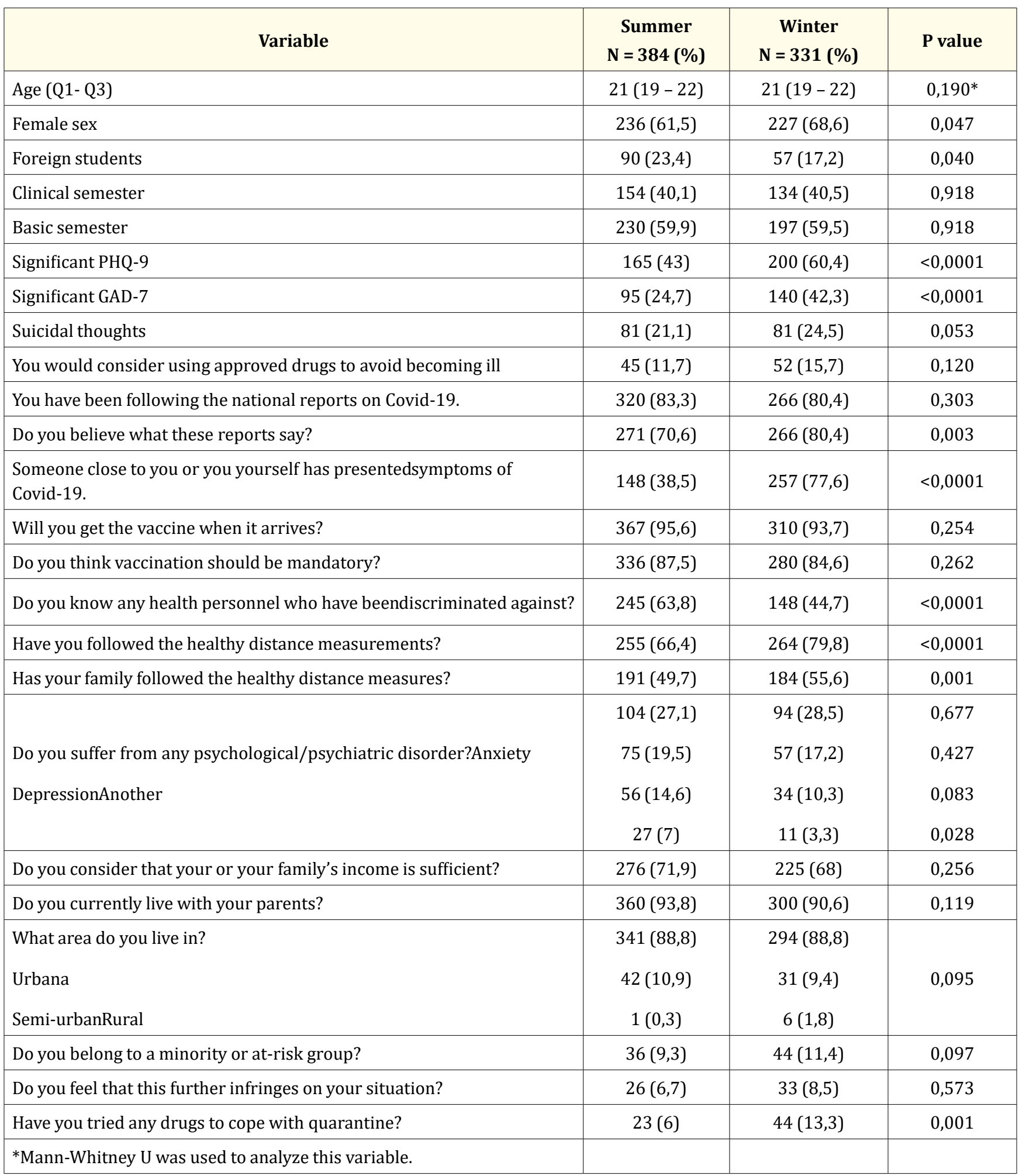

Table 1: Characteristics of the population. 


\begin{tabular}{|c|c|c|c|c|c|c|}
\hline & $\begin{array}{l}\text { Summer } \\
\text { Odds } \\
\text { Ratio }\end{array}$ & $\begin{array}{c}95 \% \\
\text { Confidence } \\
\text { Interval }\end{array}$ & P-value & $\begin{array}{l}\text { Winter } \\
\text { Odds } \\
\text { Ratio }\end{array}$ & $\begin{array}{l}\text { 95\% Confidence } \\
\text { Interval }\end{array}$ & P-value \\
\hline \multicolumn{7}{|l|}{ PHQ-9 greater than or equal to 10} \\
\hline Belong to a clinicalsemester & 0,459 & $0,299-0,702$ & 0,001 & 0,531 & $0,392-0,718$ & $<0,0001$ \\
\hline Someone close toCOVID-19 & 1,593 & $1,052-2,414$ & 0,014 & 2,103 & $1,556-2,841$ & $<0,0001$ \\
\hline Previous psychiatricdisorder & 2,537 & $1,600-4,022$ & $<0,0001$ & 2,951 & $2,081-4,186$ & $<0,0001$ \\
\hline Consider stable economy & 0,419 & $0,266-0,659$ & $<0,0001$ & 0,483 & $0,347-0,671$ & $<0,0001$ \\
\hline Use of drugs to deal withquarantine. & 2,637 & $1,090-6,379$ & 0,031 & 2,439 & $1,413-4,208$ & 0,001 \\
\hline Suicidal thinking & 5,504 & $3,312-9,672$ & $<0,0001$ & 6,298 & $4,209-9,425$ & $<0,0001$ \\
\hline GAD-7 equal to orgreater than 10 & 17,042 & $8,843-32,878$ & $<0,0001$ & 15,849 & $10,167-24,707$ & $<0,0001$ \\
\hline \multicolumn{7}{|l|}{ GAD-7 greater than or equal to 10} \\
\hline Belong to a clinicalsemester & 0,552 & $0,335-0,910$ & 0,020 & 0,675 & $0,488-0,934$ & 0,018 \\
\hline Identifying as a woman & 2,514 & $1,479-4,276$ & 0,001 & 2,070 & $1,462-2,932$ & $<0,0001$ \\
\hline $\begin{array}{l}\text { To know the medical personnel who } \\
\text { have suffered discrimination during } \\
\text { the contingency. }\end{array}$ & 1,670 & $1,003-2,780$ & 0,049 & 1,075 & $0,785-1,472$ & 0,650 \\
\hline Use of drugs to deal withquarantine. & 5,464 & $2,281-13,087$ & $<0,0001$ & 1,874 & $1,128-3,115$ & 0,015 \\
\hline Suicidal thinking & 3,472 & $2,014-5,986$ & $<0,0001$ & 3,604 & $2,533-5,129$ & $<0,0001$ \\
\hline PHQ-9 equal to orgreater than 10 & 17,042 & $8,843-32,878$ & $<0,0001$ & 15,849 & $10,167-24,707$ & $<0,0001$ \\
\hline
\end{tabular}

Table 2: Summer vs. winter odds ratio for depression and anxiety.

GAD-7 less than 10 something similar was observed as with PHQ-9 less than $10,25.7 \%$ of these do not have it any day, versus $13-1 \%$ every day. Therefore, we found that these had a significant $p$ value in all fears in general, where this relationship was observed in the majority, some in higher percentage than others. Something simi- lar happened with the "it has affected him/her" where we found variables such as "It has affected him/her/had difficulties to study" where for depression 3\% have not presented difficulties to study any day, while $45.5 \%$ have had difficulties almost every day. Respondents with PHQ-9 less than 10 had no difficulties any day in 


\begin{tabular}{|c|c|c|c|c|c|c|}
\hline During the last 2 weeks... & $\begin{array}{c}\text { PHQ-9 } \geq 10 \mathrm{~N}=200 \\
(\%)\end{array}$ & $\begin{array}{l}<10 \text { PHQ-9 } \\
\mathrm{N}=131(\%)\end{array}$ & P-Value & $\begin{array}{l}\text { GAD-7 } \geq 10 \\
\mathrm{~N}=140(\%)\end{array}$ & $\begin{array}{l}\text { GAD-7 }<10 \\
\mathrm{~N}=190(\%)\end{array}$ & P-Value \\
\hline $\begin{array}{l}\text { Fearing the death of a family } \\
\text { member }\end{array}$ & & & $<0,0001$ & & & $<0,0001$ \\
\hline $\begin{array}{l}\text { No day } \\
\text { Some days } \\
\text { Half of the days } \\
\text { Almost every day }\end{array}$ & $\begin{array}{c}26(13) \\
63(31,5) \\
53(26,5) \\
58(29)\end{array}$ & $\begin{array}{c}40(30,5) \\
54(41,2) \\
25(19,1) \\
12(9,2)\end{array}$ & & $\begin{array}{l}17(12,1) \\
40(28,6) \\
38(27,1) \\
45(32,1)\end{array}$ & $\begin{array}{l}49(25,7) \\
77(40,3) \\
40(20,9) \\
25(13,1)\end{array}$ & \\
\hline \multirow[b]{2}{*}{$\begin{array}{l}\text { Fear of infecting a family } \\
\text { member } \\
\text { No day } \\
\text { Some days } \\
\text { Half of the days } \\
\text { Almost every day }\end{array}$} & & & $<0,0001$ & & & $<0,0001$ \\
\hline & $\begin{array}{l}24(12) \\
56(28) \\
50(25) \\
70(35)\end{array}$ & $\begin{array}{l}23(17,6) \\
63(48,1) \\
31(23,7) \\
14(10,7)\end{array}$ & & $\begin{array}{l}10(7,1) \\
46(32,9) \\
30(21,4) \\
54(38,6)\end{array}$ & $\begin{array}{l}37(19,4) \\
73(38,2) \\
51(26,7) \\
30(15,7)\end{array}$ & \\
\hline \multirow{2}{*}{$\begin{array}{l}\text { Fearing that the coronavirus } \\
\text { has spread } \\
\text { No day } \\
\text { Some days } \\
\text { Half of the days } \\
\text { Almost every day }\end{array}$} & & & $<0,0001$ & & & $<0,0001$ \\
\hline & $\begin{array}{c}27(13,5) \\
50(25) \\
48(24) \\
75(37,5)\end{array}$ & $\begin{array}{l}29(22,1) \\
58(44,3) \\
29(22,1) \\
15(11,5)\end{array}$ & & $\begin{array}{l}18(12,9) \\
31(22,1) \\
33(23,6) \\
58(41,4)\end{array}$ & $\begin{array}{c}38(19,9) \\
77(40,3) \\
44(23) \\
32(16,8)\end{array}$ & \\
\hline \multirow{2}{*}{$\begin{array}{l}\text { Fear of being able to seefamily } \\
\text { members or closefriends }\end{array}$} & & & $<0,0001$ & & & $<0,0001$ \\
\hline & $\begin{array}{c}20(10) \\
37(18.5) \\
50(25) \\
93(46,5)\end{array}$ & $\begin{array}{c}32(24,4) \\
53(40.5) \\
29(22,1) \\
17(13)\end{array}$ & & $\begin{array}{c}12(8,6) \\
27(19,3) \\
30(21,4) \\
71(50,7)\end{array}$ & $\begin{array}{c}40(20,9) \\
63(33) \\
49(25,7) \\
39(20,4)\end{array}$ & \\
\hline \multirow{2}{*}{$\begin{array}{l}\text { Fear of infecting a family } \\
\text { member } \\
\text { No day }\end{array}$} & & & $<0,0001$ & & & $<0,0001$ \\
\hline & $25(12,5)$ & $28(21,4)$ & & $15(10,7)$ & $38(19,9)$ & \\
\hline Some days & $38(19)$ & $54(41,2)$ & & $25(17,9)$ & $67(35,1)$ & \\
\hline $\begin{array}{l}\text { Half of the days } \\
\text { Almost every day }\end{array}$ & $\begin{array}{c}63(31,5) \\
74(37)\end{array}$ & $\begin{array}{l}30(22,9) \\
19(14,5)\end{array}$ & & $\begin{array}{l}38(27,1) \\
62(44,3)\end{array}$ & $\begin{array}{l}55(28,8) \\
31(16,2)\end{array}$ & \\
\hline Fear of losing income & & & $<0,0001$ & & & $<0,0001$ \\
\hline
\end{tabular}




\begin{tabular}{|c|c|c|c|c|}
\hline No day & $27(13,5)$ & $42(32,1)$ & $14(10)$ & $55(28,8)$ \\
\hline Some days & $45(22,5)$ & $56(42,7)$ & $33(23,6)$ & $68(35,6)$ \\
\hline Half of the days & $56(28)$ & $25(19,1)$ & $39(27,9)$ & $42(22)$ \\
\hline Almost every day & $72(36)$ & $8(6,1)$ & $54(38,6)$ & $26(13,6)$ \\
\hline \multirow{2}{*}{$\begin{array}{l}\text { Being afraid of seeing or } \\
\text { hearing news about } \\
\text { SARS-CoV-2 }\end{array}$} & & $<0,0001$ & & 0,006 \\
\hline & $70(35)$ & $77(58.8)$ & $49(35)$ & $08(512)$ \\
\hline \multirow{3}{*}{$\begin{array}{l}\text { No day } \\
\text { Some days } \\
\text { Half of the days } \\
\text { Almost every dav }\end{array}$} & $68(34)$ & $35(26,7)$ & $48(34,5)$ & $55(28,8)$ \\
\hline & $38(19)$ & $14(10,7)$ & $24(17,1)$ & $28(14,7)$ \\
\hline & $24(12)$ & $5(3,8)$ & $19(13,6)$ & $10(5,2)$ \\
\hline $\begin{array}{l}\text { Feeling fear of needing to goto } \\
\text { the emergency room }\end{array}$ & & $<0,0001$ & & $<0,0001$ \\
\hline No day & $61(30,5)$ & $61(46,5)$ & $35(25)$ & $87(45,5)$ \\
\hline Some days & $48(24)$ & $42(32,1)$ & $41(29,3)$ & $49(25,7)$ \\
\hline \multirow{2}{*}{$\begin{array}{l}\text { Half of the days } \\
\text { Almost every day }\end{array}$} & $38(19)$ & $23(17,6)$ & $23(16,4)$ & $38(19,9)$ \\
\hline & $53(26,5)$ & $5(3,8)$ & $41(29,3)$ & $17(8,9)$ \\
\hline \multirow{2}{*}{$\begin{array}{l}\text { Fearing that you or a family } \\
\text { member will have to leave } \\
\text { home }\end{array}$} & & $<0,0001$ & & $<0,0001$ \\
\hline & & & & \\
\hline No day & $57(28,5)$ & $67(51,1)$ & $38(27,1)$ & $86(45)$ \\
\hline Some days & $55(27,5)$ & $43(32,8)$ & $35(25)$ & $63(33)$ \\
\hline Half of the days & $53(26,5)$ & $18(13,7)$ & $39(27,9)$ & $32(16,8)$ \\
\hline Almost every day & $35(17,5)$ & $3(2,3)$ & $28(20)$ & $10(5,2)$ \\
\hline Fear of dying due to Covid-19 & & $<0,0001$ & & $<0,0001$ \\
\hline No day & $69(34,5)$ & $65(49,5)$ & $51(36,4)$ & $83(43,5)$ \\
\hline Some days & $47(23,5)$ & $45(34,5)$ & $31(22,1)$ & $61(31,9)$ \\
\hline Half of the days & $40(20)$ & $14(10,7)$ & $20(14,3)$ & $34(17,8)$ \\
\hline Almost every day & $44(22)$ & $7(4,3)$ & $38(27,1)$ & $13(6,8)$ \\
\hline \multirow{2}{*}{$\begin{array}{l}\text { Having had difficulties to } \\
\text { studyNo day }\end{array}$} & & $<0,0001$ & & $<0,0001$ \\
\hline & $6(3)$ & $38(29,2)$ & $6(4,3)$ & $38(19,9)$ \\
\hline & $48(24)$ & $57(43,8)$ & $29(20,9)$ & $76(39,8)$ \\
\hline Half of the days & $55(27,5)$ & $25(19,2)$ & $36(25,9)$ & $44(23)$ \\
\hline Almost every day & $91(45,5)$ & $10(7,7)$ & $68(48,9)$ & $33(17,3)$ \\
\hline
\end{tabular}




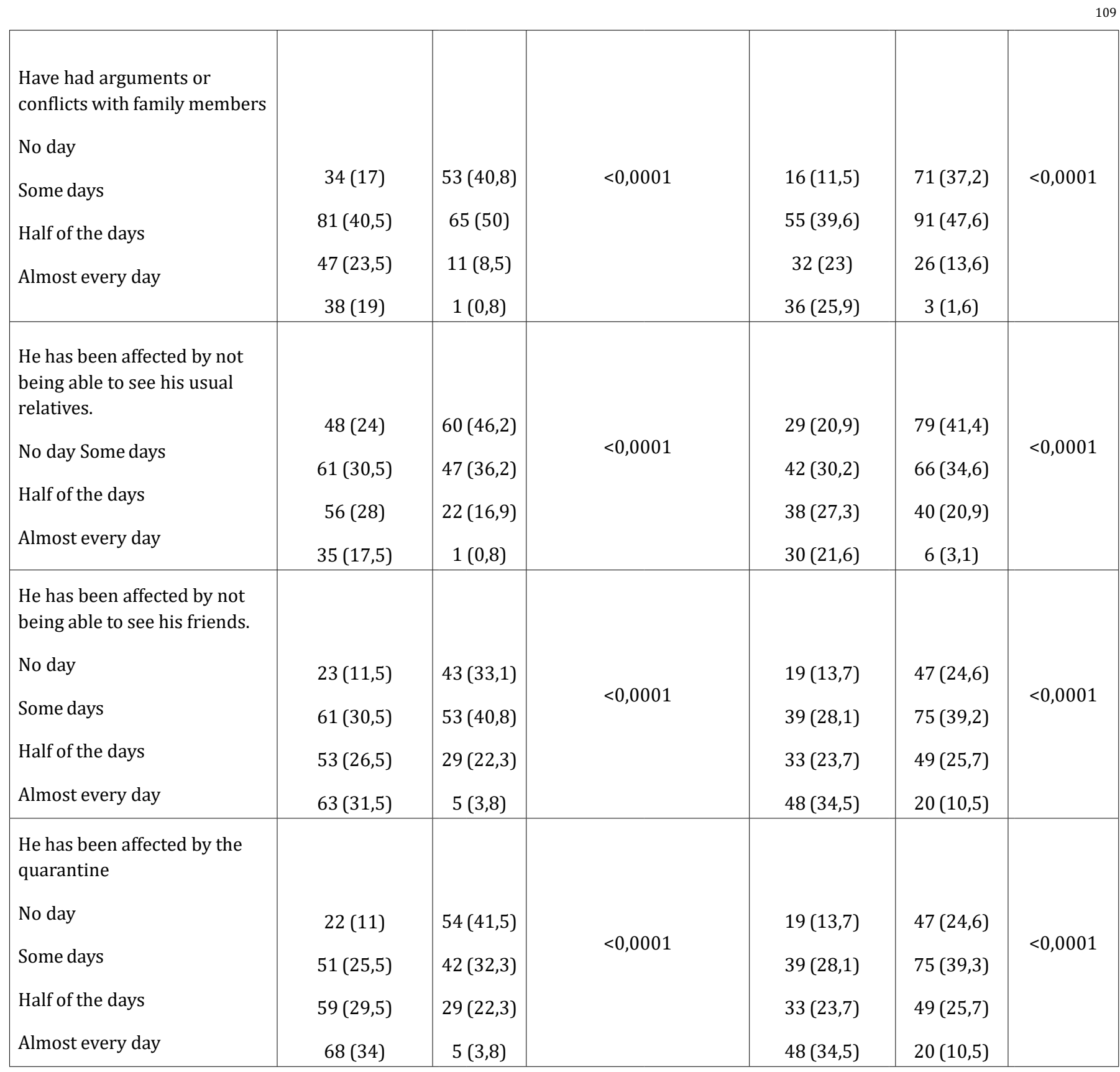

Table 3: Characteristics of depression and anxiety with CME.

$29.2 \%$ and almost every day in $7.7 \%$, reversing the relationship. For GAD-7 for anxiety, $4.3 \%$ did not present difficulties any day versus $48.9 \%$ who presented it almost every day, on the other hand, $19.9 \%$ with GAD-7 less than 10 did not present difficulties to study any day and $17.3 \%$ almost every day. The P values were significant.
Positive experiences on adversity scale (EEPA)

With the use of this scale, duality was found between those who had developed positive experiences, which were considered as protective versus those who had not, found as a risk factor in some variables such as "I have learned to organize my time better", 
"I have discovered new hobbies" and "I have become more interested in the people I care about"; in the case of anxiety, the latter does not apply. For the group with PHQ-9 greater than or equal to 10 , differences were found in those classified as protective or risk factors, such as "I have learned to organize my time better", $21 \%$ of students in the group with PHQ-9 greater than or equal to 10 mentioned that they did, compared to $42.7 \%$ of those who did not have a PHQ-9 for depression. For the second variable that was found to be protective or a risk factor referring to new activities or hobbies, the group with depression gave a positive response in $29 \%$ versus $41.2 \%$ of the group without depression. For the third variable, which was found to be protective or risk factor, "valuing and appreciating things more", a positive response was observed in $59.5 \%$ of the group with depression versus $61.1 \%$ in the group without depression. In the fourth variable, which was the last one that meant a protective or risk factor for belonging to the depres- sion group, those who reported caring more about the people they cared about was $73.5 \%$ versus $62.5 \%$ in the group without depression (the only variable where the group with depression surpassed the group without depression by more than 10 percentage points within these experiences taken as positive). On the other hand, for the group with anxiety, the first variable "I have learned to organize my time better" was present in $19.3 \%$ compared to $37.2 \%$ in the group without anxiety. In the second variable something similar was presented, for the group with anxiety, $27.1 \%$ reported new hobbies compared to $38.7 \%$ of the group without anxiety. The other variables were not found to be risk or protective factors, but in general we found that the only variable where more of the group with anxiety responded yes was "having learned to value the people they consider important", in the other variables the responses of the group without anxiety were more positive (Table 4).

\begin{tabular}{|c|c|c|c|c|c|}
\hline Variable & $\begin{array}{c}\text { PHQ-9 } \\
\geq 10 \\
N=200\end{array}$ & $\begin{array}{c}\text { PHQ-9 } \leq 10 \mathrm{~N} \\
=131\end{array}$ & $\begin{array}{c}\text { Odds ratio } \\
\text { PHQ-9 } \\
\geq 10\end{array}$ & $\begin{array}{c}95 \% \\
\text { Confidence } \\
\text { interval }\end{array}$ & P-value \\
\hline \multicolumn{6}{|c|}{ I have learned to organize my time } \\
\hline better & $42(21)$ & $56(42,7)$ & 0,336 & $0,219-0,578$ & $<0,0001$ \\
\hline Yes & $158(79)$ & $75(57,3)$ & 2,809 & $1,729-4,564$ & $<0,0001$ \\
\hline \multicolumn{6}{|l|}{ No } \\
\hline \multicolumn{6}{|c|}{ I have discovered new hobbies or } \\
\hline \multicolumn{6}{|c|}{ activities that I have never done before } \\
\hline and that I enjoy. & $58(29)$ & $54(41,2)$ & 0,582 & $0,367-0,925$ & 0,022 \\
\hline Yes & $142(71)$ & $77(58,8)$ & 1,717 & $1,081-2,728$ & 0,022 \\
\hline \multicolumn{6}{|l|}{ No } \\
\hline \multicolumn{6}{|c|}{ I have changed my scale of values and } \\
\hline \multicolumn{6}{|c|}{ now I value and appreciate things that I } \\
\hline \multicolumn{6}{|l|}{ did not before. } \\
\hline Yes & $119(59,5)$ & $80(61,1)$ & 0,937 & $0,597-1,470$ & 0,776 \\
\hline No & $81(40,5)$ & $51(38,9)$ & 1,068 & $0,680-1,676$ & 0,776 \\
\hline \multicolumn{6}{|c|}{ I have become more interested in the } \\
\hline \multicolumn{6}{|l|}{ people I care about. } \\
\hline Yes & $147(73,5)$ & $82(62,5)$ & 1,657 & $1,033-2,660$ & 0,026 \\
\hline No & $53(26,5)$ & $49(37,4)$ & 0,584 & $0,365-0,936$ & 0,026 \\
\hline \multicolumn{6}{|c|}{ I have learned to appreciate more what I } \\
\hline have & $139(69,5)$ & $81(61,8)$ & 1,407 & $0,885-2,236$ & 0,149 \\
\hline
\end{tabular}


COVID-19: Psychosocial Impact on Medical Students. Comparison of Summer-Winter Results

\begin{tabular}{|c|c|c|c|c|c|}
\hline Yes & $61(30,5)$ & $50(38,2)$ & 0,711 & $0,447-1,130$ & 0,149 \\
\hline \multicolumn{6}{|l|}{ No } \\
\hline \multicolumn{6}{|c|}{ I have learned to value personal } \\
\hline \multicolumn{6}{|c|}{ relationships more highly } \\
\hline Yes & $146(73)$ & $94(71,8)$ & 1,064 & $0,651-1,741$ & 0,804 \\
\hline No & $54(27)$ & $37(28,2)$ & 0,940 & $0,574-1,537$ & 0,804 \\
\hline \multicolumn{6}{|c|}{ I have learned to appreciate more the } \\
\hline \multicolumn{6}{|c|}{ benefits of outdoor activities. } \\
\hline Yes & $156(78)$ & $95(72,5)$ & 1,344 & $0,808-2,235$ & 0,255 \\
\hline No & $44(22)$ & $36(27,5)$ & 0,744 & $0,447-1,238$ & 0,255 \\
\hline \multicolumn{6}{|c|}{ I have enjoyed recreational activities } \\
\hline \multicolumn{6}{|c|}{ with my family members (playing cards, } \\
\hline learning to cook, etc). & $109(54,5)$ & $76(58)$ & 0,867 & $0,556-1,352$ & 0,529 \\
\hline Yes & $91(45,5)$ & $55(42)$ & 1,154 & $0,739-1,800$ & 0,529 \\
\hline \multicolumn{6}{|l|}{ No } \\
\hline & $\begin{array}{c}\text { GAD-7 } \\
\geq 10 \\
\mathrm{~N}=140\end{array}$ & $\begin{array}{c}\text { GAD-7 } \leq 10 \mathrm{~N} \\
=191\end{array}$ & $\begin{array}{l}\text { Odds ratio } \\
\text { GAD- } 7 \geq 10 \text {. }\end{array}$ & $\begin{array}{l}95 \% \\
\text { Confidence } \\
\text { interval }\end{array}$ & P-value \\
\hline \multicolumn{6}{|c|}{ I have learned to organize my time } \\
\hline better & $27(19,3)$ & $71(37,2)$ & 0,404 & $0,242-0,674$ & 0,001 \\
\hline Yes & $113(80,7)$ & $120(62,8)$ & 2,476 & $1,484-4,133$ & 0,001 \\
\hline \multicolumn{6}{|l|}{ No } \\
\hline \multicolumn{6}{|c|}{ I have discovered new hobbies or } \\
\hline \multicolumn{6}{|c|}{ activities that I have never done before } \\
\hline and that I enjoy. & $38(27,1)$ & $74(38,7)$ & 0,539 & $0,367-0,945$ & 0,028 \\
\hline Yes & $102(72,9)$ & $117(61,3)$ & 1,698 & $1,058-2,724$ & 0,028 \\
\hline \multicolumn{6}{|l|}{ No } \\
\hline \multicolumn{6}{|c|}{ I have changed my scale of values and } \\
\hline \multicolumn{6}{|c|}{ now I value and appreciate things that I } \\
\hline did not before. & $78(55,7)$ & $121(63,4)$ & 0,728 & $0,466-1,135$ & 0,161 \\
\hline Yes & $62(44,3)$ & $70(36,6)$ & 1,374 & $0,881-2,144$ & 0,161 \\
\hline \multicolumn{6}{|l|}{ No } \\
\hline \multicolumn{6}{|c|}{ I have become more interested in the } \\
\hline \multicolumn{6}{|l|}{ people I care about. } \\
\hline Yes & $98(70)$ & $131(68,6)$ & 1,069 & $0,666-1,716$ & 0,783 \\
\hline No & $42(30)$ & $60(31,4)$ & 0,913 & $0,569-1,465$ & 0,783 \\
\hline \multicolumn{6}{|c|}{ I have learned to appreciate more what I } \\
\hline have & $92(65,7)$ & $128(67)$ & 0,943 & $0,595-1,496$ & 0,804 \\
\hline Yes & $48(34,3)$ & $63(33)$ & 1,060 & $0,688-1,681$ & 0,804 \\
\hline
\end{tabular}


COVID-19: Psychosocial Impact on Medical Students. Comparison of Summer-Winter Results

\begin{tabular}{|c|c|c|c|c|c|}
\hline \multicolumn{6}{|l|}{ No } \\
\hline \multicolumn{6}{|c|}{ I have learned to value personal } \\
\hline \multicolumn{6}{|c|}{ relationships more highly } \\
\hline Yes & $101(72,1)$ & $139(72,8)$ & 0,869 & $0,595-1,578$ & 0,899 \\
\hline No & $39(27,9)$ & $52(27,2)$ & 1,032 & $0,634-1,681$ & 0,899 \\
\hline \multicolumn{6}{|c|}{ I have learned to appreciate more the } \\
\hline \multicolumn{6}{|c|}{ benefits of outdoor activities. } \\
\hline Yes & $102(72,9)$ & $149(78)$ & 0,757 & $0,456-1,255$ & 0,280 \\
\hline No & $38(27,1)$ & $42(22)$ & 1,322 & $0,797-2,192$ & 0,280 \\
\hline \multicolumn{6}{|c|}{ I have enjoyed recreational activities } \\
\hline \multicolumn{6}{|c|}{ with my family members (playing cards, } \\
\hline learning to cook, etc). & $72(51,4)$ & $113(59,2)$ & 0,731 & $0,471-1,134$ & 0,162 \\
\hline Yes & $68(48,6)$ & $78(40,8)$ & 1,368 & $0,882-2,123$ & 0,162 \\
\hline No & & & & & \\
\hline
\end{tabular}

Table 4: Aggregate odds ratio for anxiety and depression staging in Winter EEPA.

The prevalence of anxiety disorders and depressive symptoms in medical students in the Mexican population has been studied in recent years, found to be $21.9 \%$ for generalized anxiety disorder using GAD-7 (Reyes Carmona., et al. [17]) and 23\% for major depression (Morales C., et al. [18]) or 16.2\% using PHQ-9 (RomoNava, F., et al. [19]). For the world population of medical students, anxiety has been established globally a prevalence of $33.8 \%$ for anxiety according to Quek., et al. [20] while Rotenstein., et al. [21] reported a prevalence of $27.8 \%$, of depression, of which $11.1 \%$ had suicidal thoughts, Romo-Nava, F., et al. [19] reported suicidal ideation in Mexican medical students close to $10 \%$. Taking into account the percentage of the Mexican population, we found a large difference within the two groups, $21.9 \%$ vs. $24.5 \%$ and $23 \%$ vs. $43 \%$, in addition to an increase in suicidal thinking of $11.1 \%$ vs. 21.1\% during our first study, during follow-up these figures that had been shown to be higher increased significantly, from $24.5 \%$ to $42.3 \%$, and for those with depression, this increase represented from $43 \%$ to a remarkable $60.4 \%$, in addition to suicidal ideation greater than $20 \%$ in both studies, showing data of importance during the first months of the COVID-19 pandemic and almost a year later. At the beginning we mentioned that we expected to find a lower prevalence because the depressive, anxious or mixed adaptive disorders should be reduced after 9 months with the new normality but being a heterogeneous population, it should be taken into account that perhaps the depressant trigger occurred later, taking into account that the number of students who knew a close person with COVID-19 doubled, so this exclusion diagnosis should continue to be taken into account (Patra, B., et al. [22]). It is also important to highlight the existence of the so-called winter blues, which is considered an affective disorder related to the seasons of the year, the most affected are women (which we found to be the majority of our population and an established risk factor for anxiety or depression), young people, living far from the equator (our population is from northern Mexico) and with a history of mental health disorders in their families (Melrose., et al. [23]), where it is also considered that one of the possible treatments is exposure to sunlight because a possible explanation of the pathophysiology is the lack of vitamin D, so that in the case of a pandemic in which we are living, those who were previously predisposed, would have a worse course (Meesters, Y., et al. [24]), so it would also have to be taken into account as a differential diagnosis or even explain a little more the pathophysiology of these disorders during the current health contingency.

The effect of COVID-19 in the communities has been significant causing fear of contracting the disease and its derived consequences, as we can see in the CME where we observe that these fears towards COVID-19 are especially present in the population 
that shows anxiety and depression in the scales applied, although in any case we can observe that those who are not within these categories also have various related fears such as the fear of infecting loved ones or their own or their families' economic income, in addition to the affectation in the study in general. We observed that more people were in the metropolitan area currently, this may be, since the semester was supposed to be mixed, but it was impossible; so, having friends nearby but not being able to see them is something students in general could be resenting. This is especially relevant in the medical student population, most likely because of the nature of their educational career, the interdisciplinary nature of their clinical practice, and the potential risk of presenting with the disease themselves and infecting their family, demonstrated by Rastegar., et al. [25] primarily by those students in clinical semesters of the final year of internship. The social restrictions and the government's effort to curb the pandemic seem to have no effect on the young age groups (Zettler., et al. [26]), with massive gatherings of people taking place during the winter (Castillo, A. [27]), although the 25-34 age group is the one that is most infected, the one with the highest mortality is the one over 60 years of age. In any case, it was shown that students reported a good adherence to health measures even in this follow-up, it was shown that a higher percentage believed that both they and their families adhered completely compared to the summer follow-up; the fear of getting sick and making their family sick as well as the fear of having problems with family finances, which were prevalent according to the EMC, could have an influence. Women were more likely to belong to the group with anxiety and/or depression, similar to what was found by Liu., et al. [28] Nakhostin-Ansari., et al. [29] and Pieh., et al. [30] contrasting with Cao., et al. [2].

\section{Conclusion}

What makes our study unique is the focus on medical students, a group considered at risk, the use of established scales for the pandemic, the EMC and the EEPA and the search for protective and risk factors. Within the EEPA responses we have seen that only one was more present in those with depression and that curiously is to place more value on their loved ones "I value more the people I care about" and when looking at it with the EMC "I am afraid of infecting my family and friends" we observe an important relationship of the feelings of medical students with their close groups. We also see that the valuation of outdoor activities was highlighted, being quite present in the 4 groups, we see that, although the pandemic has brought positive things, the negative ones prevail. The limitations of this study are the specificity of the population studied, lack of comparison with students of other careers or with the general population. Likewise, it seems pertinent to us to attribute the high levels of depression and anxiety to the methodology used to obtain the responses (virtually). Almost $14 \%$ of the students who answered in the summer were lost, so the students who answered on this occasion may probably be those who were more involved or identified in the first one and that is why this increase was found. In any case, it should be noted that this increase was not only in percentage, but also in number.

It is necessary to pay attention to the data obtained with the use of these scales (although they are screening and not diagnostic, they are an important guiding test), the main interest should be paid to the search for the creation of screening instruments that are validated not in the context of a pandemic, but as virtual tools that show a high degree of sensitivity and specialty. We believe that it is necessary to create virtual programs for the promotion of mental health in medical students, favoring adaptability and resilience.

\section{Acknowledgements}

Marcelo-Barrientos, Guillan, Saucedo-Charles, Luis, PolinaLugo, Rebeca, Elizalde-Ojeda, Jorge, Martínez-Rodríguez, Cristian, López-Ayala, Marcela, Zamayoa-Torres, Jorge. González-Galván, Celica, Sosa-Colunga, Alexis, Navarrete-Juárez, Manuel, GómezLópez, Humberto, De La Garza-Manrique, Paula, Delgado-Banda, Angel, Galicia-Carriles, Ricardo, Cavazos-Guerrero Clarissa, OrtegaMoreno, Diego, Tello-Medoza, Ricardo*.

\section{Conflict of Interest}

The authors declare that they have no conflicts of interest.

\section{Bibliography}

1. Secretaria de Salud. "Exceso de Mortalidad en México" (2021).

2. Cao Wenjun., et al. "The psychological impact of the COVID-19 epidemic on college students in China". Psychiatry Research 287 (2020): 112934.

3. Li Yuchen., et al. "Psychological distress among health professional students during the COVID-19 outbreak". Psychological Medicine (2020): 1-3. 
4. Meo Sultan Ayoub., et al. "COVID-19 Pandemic: Impact of Quarantine on Medical Students' Mental Wellbeing and Learning Behaviors". Pakistan Journal of Medical Sciences 36 (2020): S43-S48.

5. Ferrel Meganne N and John J Ryan. "The Impact of COVID-19 on Medical Education". Cureus 123 (2020): e7492.

6. Alsoufi Ahmed., et al. "Impact of the COVID-19 pandemic on medical education: Medical students' knowledge, attitudes, and practices regarding electronic learning". PloS one 15.11 (2020): e0242905.

7. Ngo HG., et al. "COVID-19: Using Social Media to Promote Mental Health in Medical School During the Pandemic". International Journal of Medical Students 8.3 (2020): 305-306.

8. Pérez Abreu MR., et al. "Alteraciones psicológicas en estudiantes de medicina durante la pesquisa activa de la COVID-19". MEDISAN (2020): 537-548.

9. Pizan-Campos E., et al. "Impact of covid-19 on the education of medical students in Peru". Revista de la Facultad de Medicina Humana (2020): 534-535.

10. Garcia-Espinosa P., et al. "Covid-19, Impacto Psicosocial En Estudiantes De Medicina”. Salud Pública De México (2021).

11. Sandín Bonifacio., et al. "Impacto psicológico de la pandemia de COVID-19: Efectos negativos y positivos en población española asociados al periodo de confinamiento nacional". Revista de Psicopatología y Psicología Clínica [En línea] 25.1 (2020): $1-22$.

12. Löwe B., et al. "Validation and standardization of the Generalized Anxiety Disorder Screener (GAD-7) in the general population". Medical Care (2008).

13. Spitzer Robert L., et al. "A brief measure for assessing generalized anxiety disorder: the GAD-7". Archives of Internal Medicine 166.10 (2006): 1092-1097.

14. Spitzer R L., et al. "Validation and utility of a self-report version of PRIME-MD: the PHQ primary care study. Primary Care Evaluation of Mental Disorders. Patient Health Questionnaire". JAMA 282.18 (1999): 1737-1744.
15. Kroenke K, Spitzer RL, Williams JB. The PHQ-9: validity of a brief depression severity measure". Journal of General Internal Medicine 16.9 (2001): 606-613.

16. IBM Corp. IBM SPSS Statistics for Windows, Version 26.0. Armonk, NY: IBM Corp (2017).

17. Carmona Carlos., et al. "Ansiedad De Los Estudiantes De Una Facultad De Medicina Mexicana, Antes De Iniciar El Internado". Investigación en Educación Médica 6 (2016).

18. Morales Claudia., et al. "Síntomas Depresivos Y Rendimiento Escolar En Estudiantes De Medicina”. Salud Mental 36 (2013).

19. Romo-Nava Francisco., et al. "Major depressive disorder in Mexican medical students and associated factors: A focus on current and past abuse experiences". Journal of Affective Disorders 245 (2019): 834-840.

20. Quek Travis Tian-Ci., et al. "The Global Prevalence of Anxiety among Medical Students: A Meta-Analysis". International Journal of Environmental Research and Public Health 16.15 (2019): 2735.

21. Rotenstein Lisa S., et al. "Prevalence of Depression, Depressive Symptoms, and Suicidal Ideation Among Medical Students: A Systematic Review and Meta-Analysis". JAMA 316.21 (2016): 2214-2236.

22. Patra Bichitra Nanda and Siddharth Sarkar. "Adjustment disorder: current diagnostic status". Indian Journal of Psychological Medicine 35.1 (2013): 4-9.

23. Melrose Sherri. "Seasonal Affective Disorder: An Overview of Assessment and Treatment Approaches". Depression Research and Treatment 2015 (2015): 178564.

24. Meesters Ybe and Marijke Cm Gordijn. "Seasonal Affective Disorder, Winter Type: Current Insights and Treatment Options". Psychology Research and Behavior Management 9 (2016): 317 327.

25. Rastegar Kazerooni AmirAli., et al. "Peer mentoring for medical students during the COVID-19 pandemic via a social media platform". Medical Education 54.8 (2020): 762-763. 
26. Zettler Ingo., et al. "The Role of Personality in Covid-19-Related Perceptions, Evaluations, and Behaviors: Findings across Five Samples, Nine Traits, and 17 Criteria". Social Psychological and Personality Science (2021): 19485506211001680.

27. Castillo A. Condena Manuel de la O fiesta "rave" en Santiago, NL. (2021).

28. Liu Nianqi., et al. "Prevalence and predictors of PTSS during COVID-19 outbreak in China hardest-hit areas: Gender differences matter". Psychiatry Research 287 (2020): 112921.

29. Nakhostin-Ansari Amin., et al. "Depression and Anxiety among Iranian Medical Students during COVID-19 Pandemic". Iranian Journal Of Psychiatry 15.3 (2020): 228-235.

30. Pieh Christoph., et al. "The effect of age, gender, income, work, and physical activity on mental health during coronavirus disease (COVID-19) lockdown in Austria". Journal of Psychosomatic Research 136 (2020): 110186.

Volume 4 Issue 6 June 2021

(C) All rights are reserved by Patricio García-Espinosa.,

et al. 